\title{
DYNAMIC NEUTRON DIFFRACTION STUDY OF THERMAL STABILITY AND SELF- RECOVERY IN ALUMINIUM TITANATE
}

I.M. Low and Z. Oo

Department of Imaging \& Applied Physics, Curtin University of Technology, GPO Box U1987, Perth, WA 6845, Australia

\section{ABSTRACT}

Aluminium titanate $\left(\mathrm{Al}_{2} \mathrm{TiO}_{5}\right)$ is an excellent refractory and thermal shock resistant material due to its relatively low thermal expansion coefficient and high melting point. However, $\mathrm{Al}_{2} \mathrm{TiO}_{5}$ unstable and undergoes a eutectoid-like decomposition to $\alpha-\mathrm{Al}_{2} \mathrm{O}_{3}$ and $\mathrm{TiO}_{2}$ (rutile) at the temperature range of $900-1280^{\circ} \mathrm{C}$. In this paper, we describe the use of high-temperature neutron diffraction to study (a) the phenomenon of self-recovery in decomposed $\mathrm{Al}_{2} \mathrm{TiO}_{5}$, and (b) the role of grain size on the rate of isothermal decomposition at $1100^{\circ} \mathrm{C}$. It is shown that the process of decomposition in $\mathrm{Al}_{2} \mathrm{TiO}_{5}$ is reversible whereby self-recovery occurs readily when decomposed $\mathrm{Al}_{2} \mathrm{TiO}_{5}$ is re-heated above $1300^{\circ} \mathrm{C}$, and the rate of phase decomposition increases as the grain size decreases.

\section{INTRODUCTION}

Aluminium titanate $\left(\mathrm{Al}_{2} \mathrm{TiO}_{5}\right)$ is an excellent refractory and thermal shock resistant material due to its relatively low thermal expansion coefficient $\left(\sim 1 \times 10^{-6}{ }^{\circ} \mathrm{C}^{-1}\right)$ and high melting point $\left(1860^{\circ} \mathrm{C}\right)$. It is one of several materials which is isomorphous with the mineral pseudobrookite $\left(\mathrm{Fe}_{2} \mathrm{TiO}_{5}\right){ }^{1,2}$ In this structure, each $\mathrm{Al}^{3+}$ or $\mathrm{Ti}^{4+}$ cation is surrounded by six oxygen ions forming distorted oxygen octahedra. These $\mathrm{AlO}_{6}$ or $\mathrm{TiO}_{6}$ octahedra form (001) oriented double chains weakly bonded by shared edges. This structural feature is responsible for the strong thermal expansion anisotropy which generates localised internal stresses to cause severe microcracking. Although this microcracking weakens the material, it imparts a desirable low thermal expansion coefficient and an excellent thermal shock resistance.

At elevated temperature, $\mathrm{Al}_{2} \mathrm{TiO}_{5}$ is only thermodynamically stable above $1280^{\circ} \mathrm{C}$ and undergoes a eutectoid-like decomposition to $\alpha-\mathrm{Al}_{2} \mathrm{O}_{3}$ and $\mathrm{TiO}_{2}$ (rutile) within the temperature range 900$1280^{\circ} \mathrm{C}$. ${ }^{3-11}$ This undesirable decomposition has limited its wider application. Hitherto, the role of grain size on the rate of phase decomposition is poorly understood but experimental evidences suggest a nucleation and growth controlled process. It is generally agreed that the decomposition rate peaks at $1100^{\circ} \mathrm{C}$ and that residual alumina particles might act as preferred nucleation sites for the decomposition. ${ }^{3}$

In recent studies by Low and co-workers, ${ }^{12-15}$ microstructure and furnace atmosphere have been observed to have a profound influence on the thermal stability of $\mathrm{Al}_{2} \mathrm{TiO}_{5}$. For instance, the decomposition rate of $\mathrm{Al}_{2} \mathrm{TiO}_{5}$ at $1100^{\circ} \mathrm{C}$ is significantly enhanced in vacuum (10 ${ }^{-4}$ torr) or argon where $>90 \%$ of $\mathrm{Al}_{2} \mathrm{TiO}_{5}$ decomposed after only $4 \mathrm{~h}$ soaking when compared to less than $10 \%$ in atmospheric air. ${ }^{12-14}$ This suggests that the process of decomposition of $\mathrm{Al}_{2} \mathrm{TiO}_{5}$ is susceptible to environmental attack or sensitive to the variations in the oxygen partial pressure during ageing. The stark contrast in the mechanism of phase decomposition is believed to arise from the vast differences in the oxygen partial pressure that exists between air and vacuum.

A similar phenomenon, although less profound, has been observed for $\mathrm{Al}_{2} \mathrm{TiO}_{5}$ with a distinct difference in grain size. However, it is unclear whether there is a critical grain size associated with this phenomenon. The reason for this grain-size effect is unclear at this stage although it may be closely related to its greater tendency for microcracking as the grain size increases. The microcracking 
phenomenon is closely related to the material microstructure and thermal expansion anisotropy. ${ }^{16-18}$ Below a critical grain size, the elastic energy of the system is insufficient to nucleate microcracks during cooling and thus causing no degradation to the mechanical strength. The density of microcracks increases drastically with grain size once the critical value is exceeded.

In this paper, we present results on the role of grain size on the isothermal stability of $\mathrm{Al}_{2} \mathrm{TiO}_{5}$ at $1100^{\circ} \mathrm{C}$ as well as its capability to self-recover when it is reheated following decomposition. The temperature-dependent thermal stability and isothermal decomposition of $\mathrm{Al}_{2} \mathrm{TiO}_{5}$ have been dynamically monitored and characterized using neutron diffraction to study the structural changes occurring during phase decomposition in real time.

\section{EXPERIMENTAL METHODS}

Sample Preparation

The starting powders used for the synthesis of $\mathrm{Al}_{2} \mathrm{TiO}_{5}$ (AT) consisted of high purity commercial alumina $\left(99.9 \% \mathrm{Al}_{2} \mathrm{O}_{3}\right)$ and rutile $\left(99.5 \% \mathrm{TiO}_{2}\right)$. One mole of alumina powder and one mole of rutile powder were initially mixed using a mortar and pestle. The powder mixture was then wet mixed in ethanol using a Turbula mixer for $2.0 \mathrm{~h}$. The slurry was then dried in a ventilated oven at $100^{\circ} \mathrm{C}$ for 24 h. The dried powder was uniaxially-pressed in a steel die at $150 \mathrm{MPa}$ to form cylindrical bars of length $20 \mathrm{~mm}$ and diameter $15 \mathrm{~mm}$, followed by sintering in a air-ventilated furnace at (a) $1400^{\circ} \mathrm{C}$ in air for 1 $\mathrm{h}$ to achieve a fine-grained (FG) microstructure $(\sim 1-3 \mu \mathrm{m})$; (b) $1500^{\circ} \mathrm{C}$ in air for $2 \mathrm{~h}$ to achieve a medium-grained (MG) microstructure $(\sim 5-10 \mu \mathrm{m})$, and (c) $1600^{\circ} \mathrm{C}$ in air for $4 \mathrm{~h}$ to achieve coarsegrained (CG) $(\sim 30-50 \mu \mathrm{m}) \mathrm{Al}_{2} \mathrm{TiO}_{5}$.

Neutron Diffraction (ND)

A medium resolution powder diffractometer (MRPD) located at the Australian Nuclear Science and Technology Organization (ANSTO) in Lucas Heights, NSW was used for neutron diffraction study of the thermal stability of $\mathrm{Al}_{2} \mathrm{TiO}_{5}$. The effect of grain size on the isothermal stability of $\mathrm{Al}_{2} \mathrm{TiO}_{5}$ was dynamically monitored at $1100^{\circ} \mathrm{C}$ in air atmosphere for up to 10 hours. A decomposed medium-grained $\mathrm{Al}_{2} \mathrm{TiO}_{5}$ sample was used for the study of self-recovery by reheating it from room temeperature to $1450^{\circ} \mathrm{C}$. In addition, the temperature range and the onset of thermal decomposition of $\mathrm{Al}_{2} \mathrm{TiO}_{5}$ in the temperature range $20-1400^{\circ} \mathrm{C}$ was investigated. The operation conditions of the MRPD were $\lambda=$ $1.667 \AA$, $2 \theta$ range $=4-138^{\circ}$, step size $=0.1^{\circ}$, counting time $\sim 40-50 \mathrm{~s} / \mathrm{step}$, monochromator of $8 \mathrm{Ge}$ crystals (115 reflection), and $32{ }^{3}$ He detectors $4^{\circ}$ apart. The relative abundance of phases present was computed using the Rietveld method. The models used to calculate the phase abundance for MRPD were Maslen et al. ${ }^{19}$ for alumina, Epicier et al. ${ }^{20}$ for $\mathrm{Al}_{2} \mathrm{TiO}_{5}$, and Howard et al. ${ }^{21}$ for rutile. The software used to analyze the data was Rietica 1.7.7.

\section{RESULTS AND DISCUSSION}

\section{Effect of Grain Size on Phase Stability}

Figure 1 shows the typical neutron diffraction plots of $\mathrm{Al}_{2} \mathrm{TiO}_{5}$ with $\mathrm{CG}$ and $\mathrm{MG}$ microstructures before and after thermal decomposition at $1100^{\circ} \mathrm{C}$ for $10 \mathrm{~h}$ to form corundum and rutile. The corresponding diffraction plots for the FG sample are shown in Fig. 2. The good quality of Rietveld refinement plots for three samples are shown in Fig. 3 where "goodness-of-fits" of between 2.5 -3.5 were achieved. The Bragg factors $\left(\mathrm{R}_{\mathrm{B}}\right)$ obtained for corundum, $\mathrm{Al}_{2} \mathrm{TiO}_{5}$ and rutile were between 2-5 2.7, $3.0-3.2$, and $1.9-2.1$ respectively. 


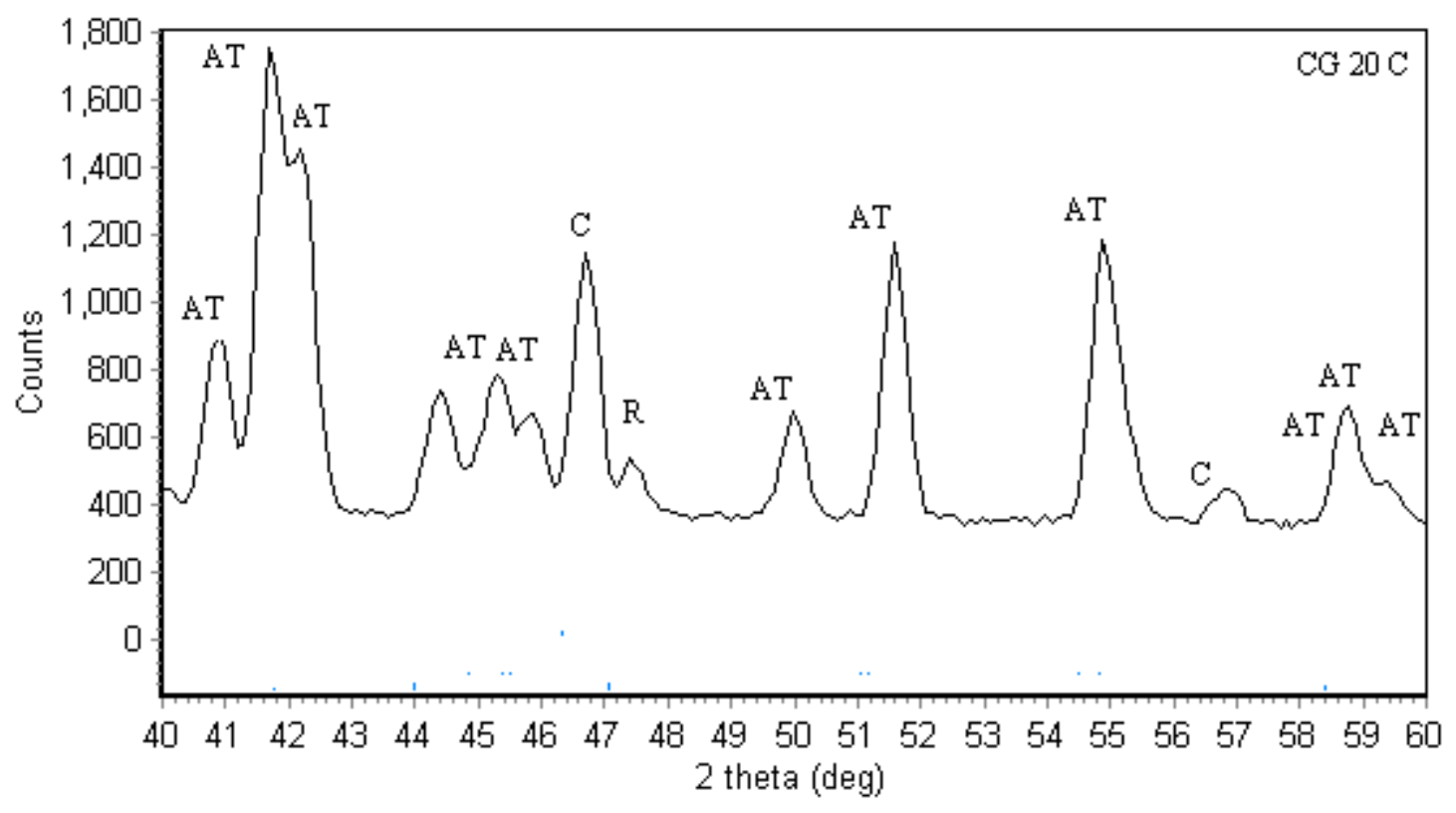

(a)

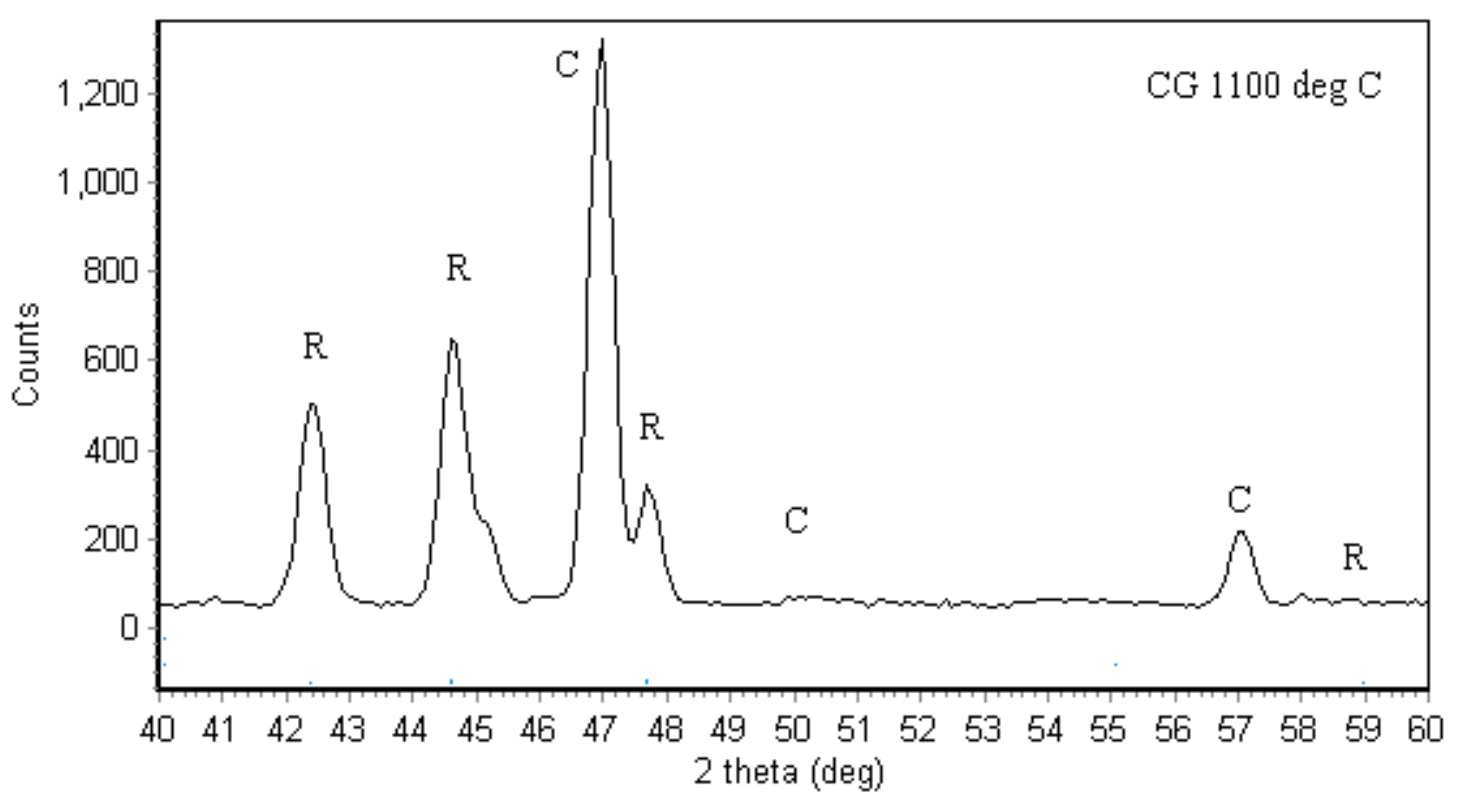

(b)

Fig. 1: Typical neutron diffraction plots of as-sintered CG or $\mathrm{MG}_{2} \mathrm{Al}_{2} \mathrm{TiO}_{5}$ (a) before and (b) after isothermal decomposition at $1100^{\circ} \mathrm{C}$ for $10 \mathrm{~h}$. [Legend: $\mathrm{AT}=\mathrm{Al}_{2} \mathrm{TiO}_{5} ; \mathrm{C}=$ corundum; $\mathrm{R}=$ rutile] 


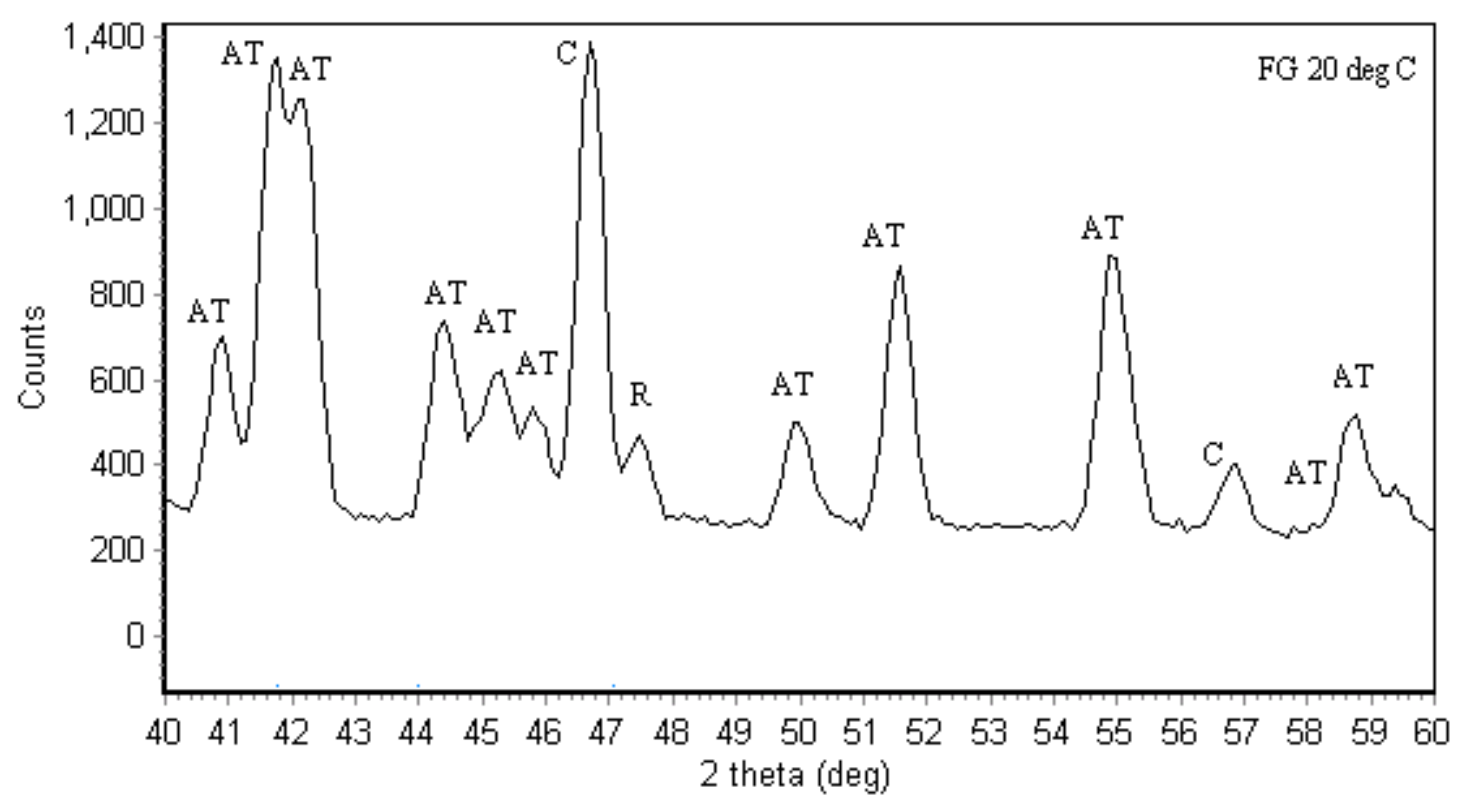

(a)

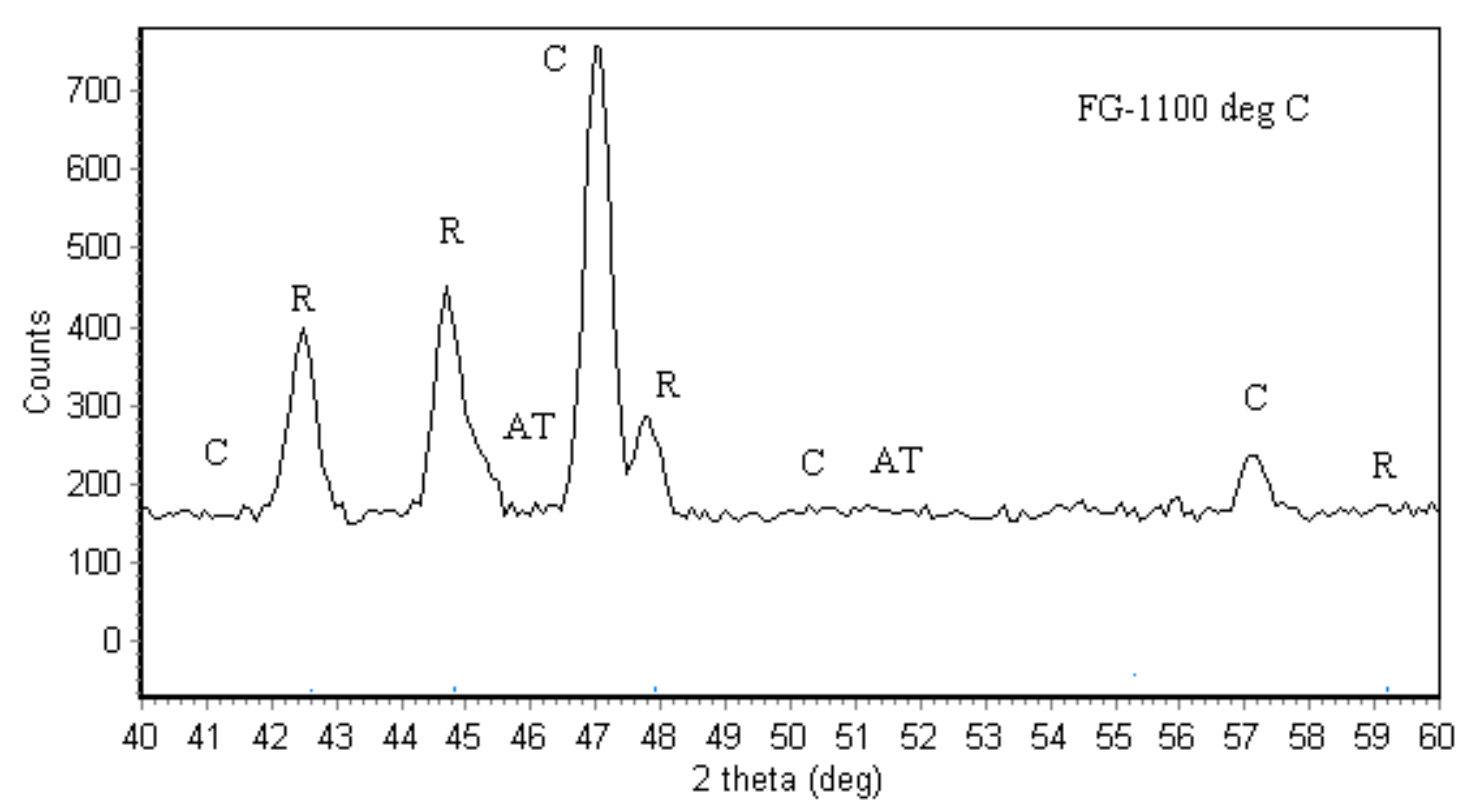

(b)

Fig. 2: Typical neutron diffraction plots of as-sintered $\mathrm{FG} \mathrm{Al}_{2} \mathrm{TiO}_{5}$ (a) before and (b) after isothermal decomposition at $1100^{\circ} \mathrm{C}$ for $10 \mathrm{~h}$. [Legend: $\mathrm{AT}=\mathrm{Al}_{2} \mathrm{TiO}_{5} ; \mathrm{C}=$ corundum; $\mathrm{R}=$ rutile] 

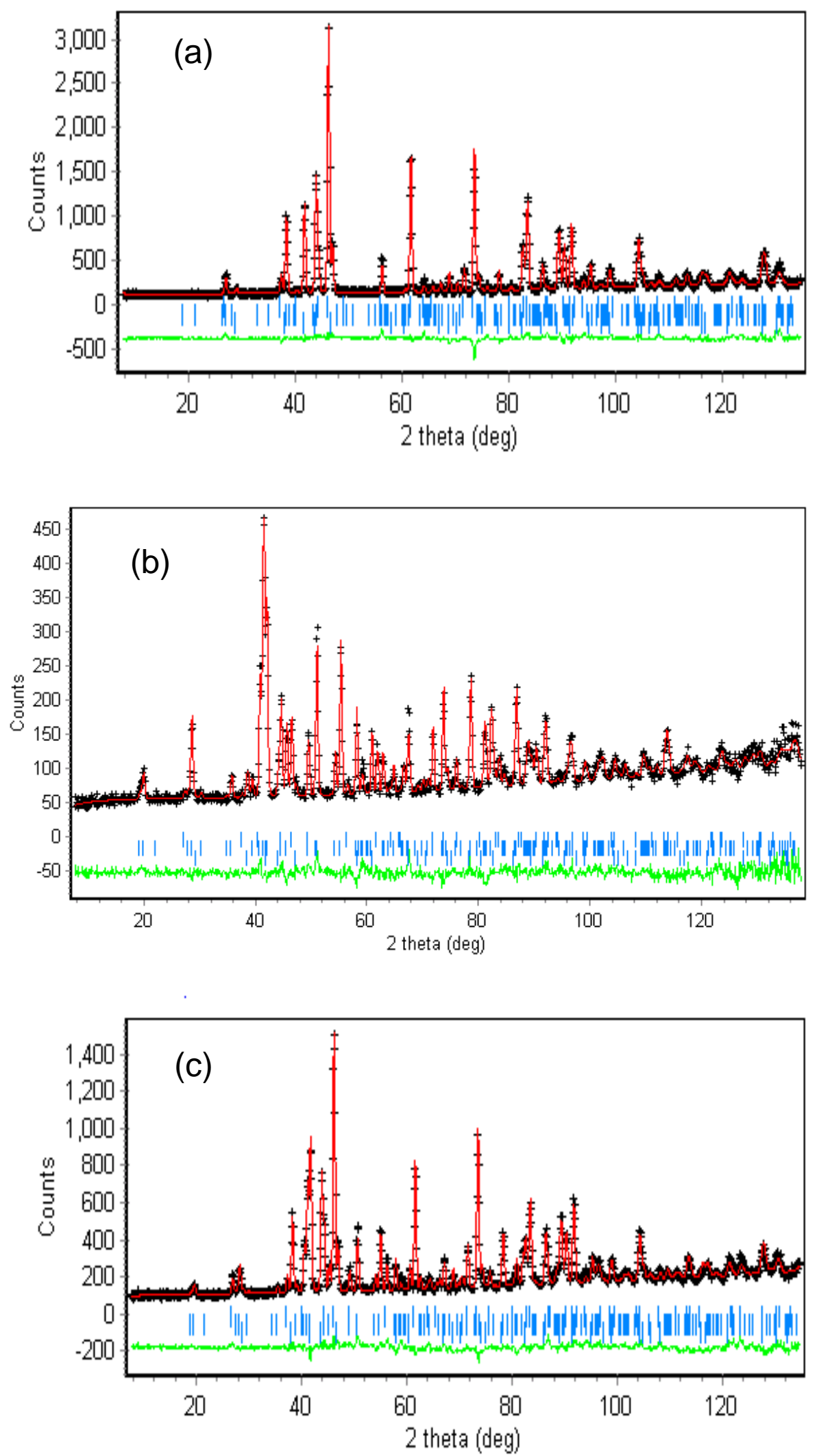

Fig. 3: Rietveld refinement plots of $\mathrm{Al}_{2} \mathrm{TiO}_{5}$ after isothermal decomposition at $1100^{\circ} \mathrm{C}$ : (a) $\mathrm{FG}$, (b) $\mathrm{MG}$, and (c) CG. 
The profound effect of grain size on the isothermal stability of in air at $1100^{\circ} \mathrm{C}$ is revealed in Fig. 4. Clearly, coarse-grained $\mathrm{Al}_{2} \mathrm{TiO}_{5}$ exhibits a slowest rate of thermal decomposition when compared to its medium-grained and fine-grained counterparts. To the best of our knowledge, this is the first time that grain size has been shown to affect the propensity of thermal degradation in $\mathrm{Al}_{2} \mathrm{TiO}_{5}$. However, it is unclear whether there is a critical grain size associated with this phenomenon. The reason for this grain-size effect is unclear at this stage although it may be closely related to its greater tendency for stress-relief through microcracking as the grain size increases. The microcracking phenomenon is closely related to the material microstructure and thermal expansion anisotropy. ${ }^{13-15}$ Below a critical grain size, the elastic energy of the system is insufficient to nucleate microcracks during cooling and thus causing no degradation to the mechanical strength. The density of microcracks increases drastically with concomitant stress-relief once the grain size exceeds a critical value. It is hypothesized that the release of residual stresses helps to reduce phase decomposition.

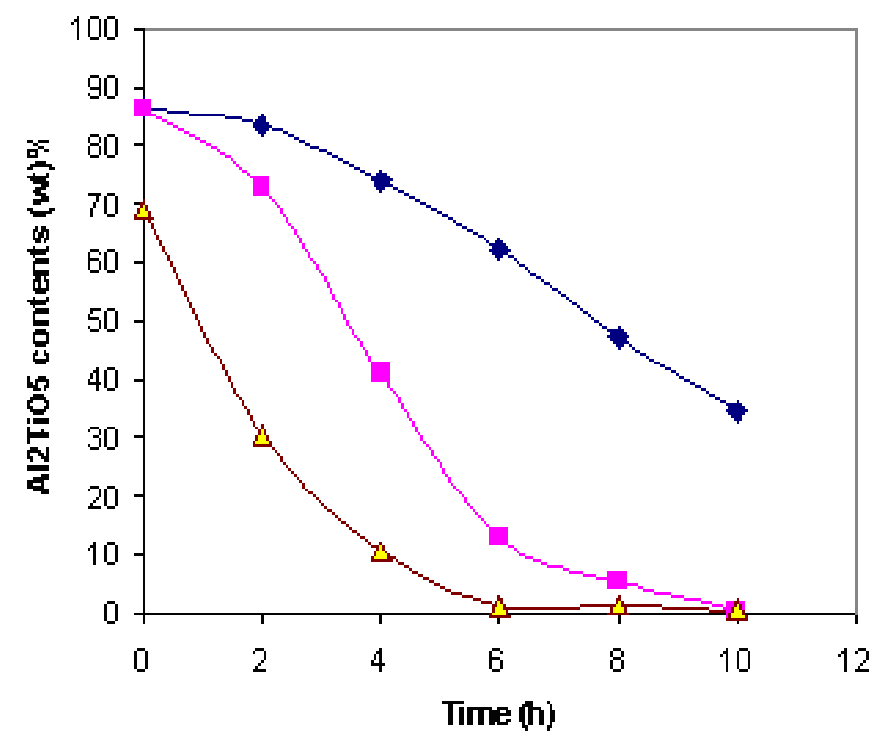

Fig. 4: Effect of $\mathrm{Al}_{2} \mathrm{TiO}_{5}$ grain size on the propensity of isothermal decomposition at $1100^{\circ} \mathrm{C}$ in air.

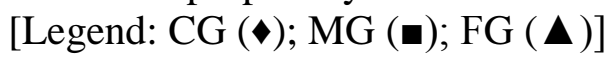

Fig. 5 (a) shows the typical microstructure of as-sintered coarse-grained AT prior to isothermal ageing where the presence of fine microcracks within certain grains is clearly evident. The formation of these microcracks can be attributed to the pronounced thermal expansion anisotropy of AT during cooling from an elevated temperature. The formation of these stress-relief microcracks is believed to impart a low fracture strength but high thermal shock resistance to AT and improved thermal stability. Following isothermal-ageing in air at $1000^{\circ} \mathrm{C}$ for $10 \mathrm{~h}$, both needle-like and angular particles could be seen to form on the surface of $\mathrm{Al}_{2} \mathrm{TiO}_{5}$ grains (Fig. 5b). Based on the energy dispersive spectrocopy (EDS) results, ${ }^{15}$ these nano-sized particles were identified as surface by-products (ie. $\mathrm{Al}_{2} \mathrm{O}_{3}$ and $\mathrm{TiO}_{2}$ ) of thermally decomposed AT. This may indicate that the initial nucleation process of thermal decomposition of AT is surface-initiated and the growth kinetics are diffusion-controlled or temperature and time dependent. 

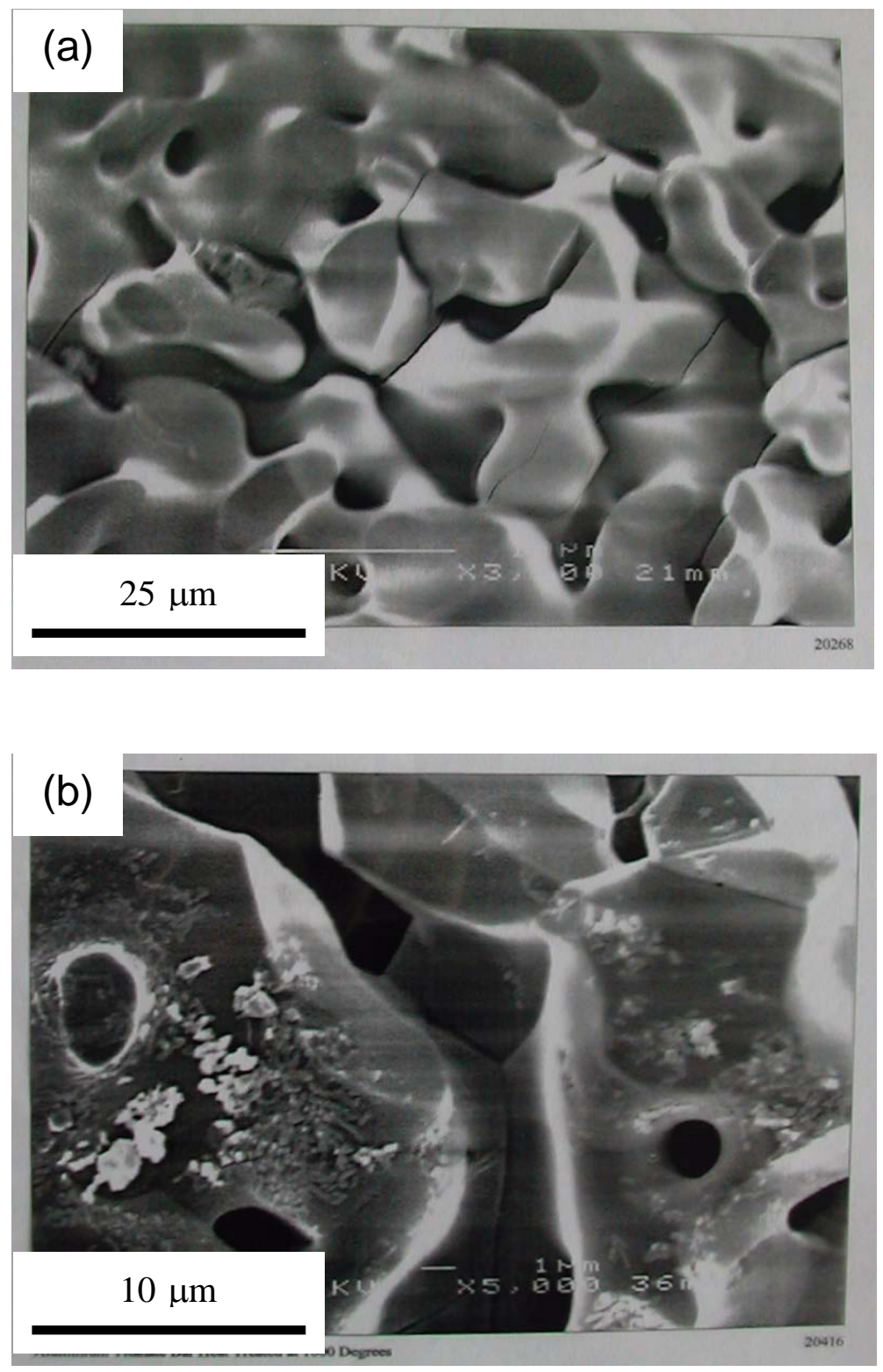

Fig. 5: Scanning electron micrographs of coarse-grained AT (a) before decomposition and (b) after isothermal decomposition at $1100^{\circ} \mathrm{C}$. Note the presence of microcracks within certain grains in (a).

The stark contrast in the microstructures of decomposed $\mathrm{Al}_{2} \mathrm{TiO}_{5}$ with different grain sizes is shown in Figure 6. The light regions in the microstructures indicate the locations of rutile grains following phase decomposition of $\mathrm{Al}_{2} \mathrm{TiO}_{5}$. A large amount of rutile can be seen in the fine-grained sample which indicates extensive phase decomposition (Fig. 6a). As the microstructure becomes coarser, the degree of phase decomposition appears to become less and is least in the coarse-grained sample (Fig. 6a). This observation is consistent with the neutron diffraction results shown in Fig. 3 above. However, the implication of this work may be a deterrent to materials scientists to develop highstrength nano-structured $\mathrm{Al}_{2} \mathrm{TiO}_{5}$ which might be highly susceptible to phase decomposition, unless it is stabilized by additives such as $\mathrm{MgO}, \mathrm{Fe}_{2} \mathrm{O}_{3}$ and $\mathrm{SiO}_{2}$. 

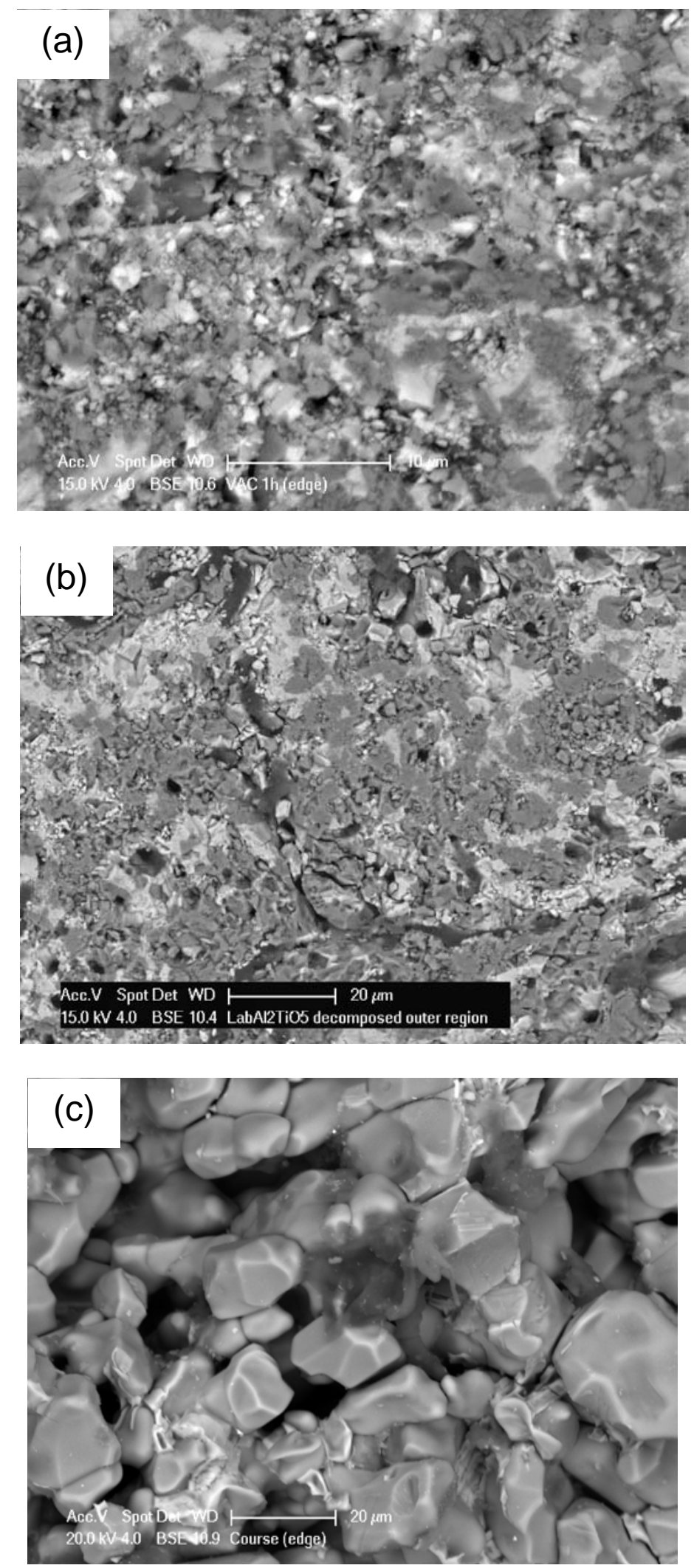

Fig. 6: Scanning electron micrographs showing the microstructures of decomposed $\mathrm{Al}_{2} \mathrm{TiO}_{5}$ with different grain sizes: (a) FG, (b) MG, and (c) CG. Note the increasing degree of phase decomposition as the grain size decreases from (c) to (a). 


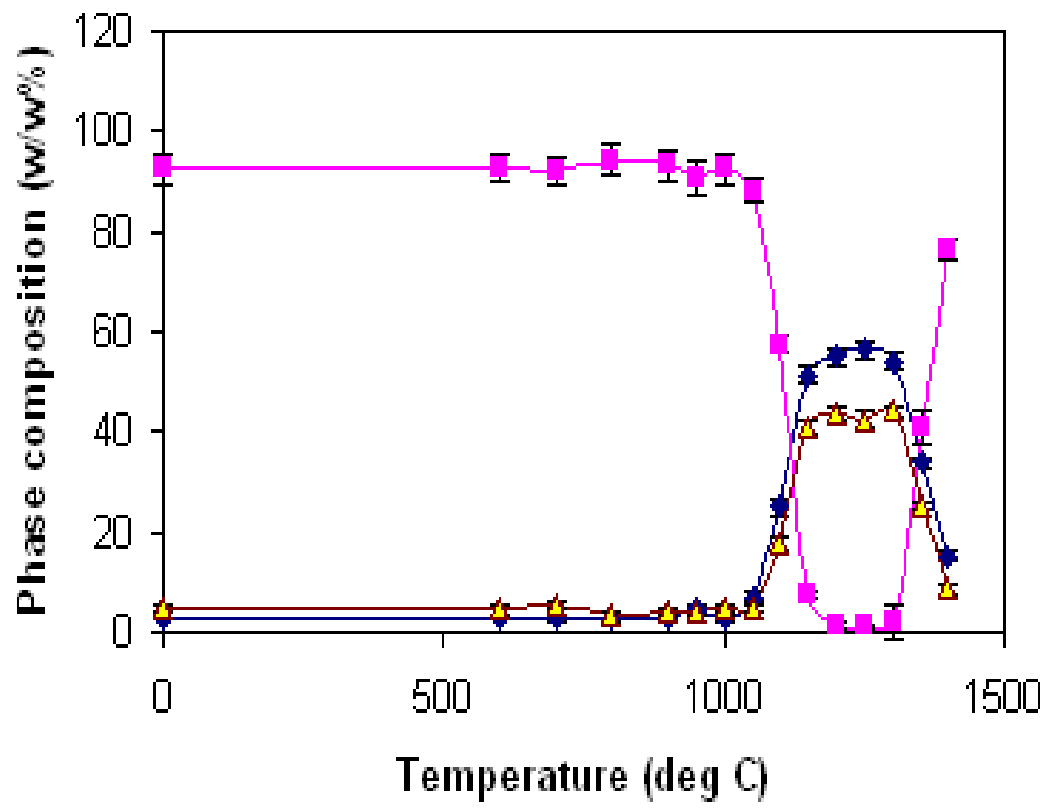

Fig. 7: Thermal stability of $\mathrm{Al}_{2} \mathrm{TiO}_{5}$ over $20-1400^{\circ} \mathrm{C}$ as revealed by high-temperature neutron diffraction. Note the display of pronounced thermal decomposition at $\sim 1100-1300^{\circ} \mathrm{C}$. Errors bars indicate two estimated standard deviations $\pm 2 \sigma$. [Legend: $=\mathrm{Al}_{2} \mathrm{TiO}_{5} ; \bullet=\mathrm{Al}_{2} \mathrm{O}_{3} ; \Delta=\mathrm{TiO}_{2}$ ]

\section{Phenomenon of Self-Recovery}

The thermal stability of $\mathrm{Al}_{2} \mathrm{TiO}_{5}$ in the temperature range $20-1400^{\circ} \mathrm{C}$ as revealed by neutron diffraction is shown in Fig. 7. Clearly, $\mathrm{Al}_{2} \mathrm{TiO}_{5}$ is stable up to $\sim 1100^{\circ} \mathrm{C}$ and becomes unstable at between $\sim 1150-1300^{\circ} \mathrm{C}$. Beyond $1300^{\circ} \mathrm{C}$, the thermal decomposition is arrested and the phase stability is restored. This implies that the process of thermal decomposition is reversible or recoverable provided the restricted temperature range of between $\sim 1100-1300^{\circ} \mathrm{C}$ is not transgressed. This process of self-recovery or reversible reaction can be described as follows:

$$
\mathrm{Al}_{2} \mathrm{O}_{3}+\mathrm{TiO}_{2} \leftrightarrow \mathrm{Al}_{2} \mathrm{TiO}_{5}
$$

Figure 8 provides further evidence of self-recovery in decomposed $\mathrm{Al}_{2} \mathrm{TiO}_{5}$ when it was reheated from room temperature to $1450^{\circ} \mathrm{C}$ for $2 \mathrm{~h}$. It is clearly shown that self-recovery takes place through the rapid reaction of corundum and rutile to form $\mathrm{Al}_{2} \mathrm{TiO}_{5}$ with $>98 \mathrm{wt} \%$ phase purity. This capability of self-recovery further suggests the process of decomposition is spontaneous and reversible as indicated in Equation (1). The implication of this phenomenon is far-reaching whereby it may be possible to restore the decomposed $\mathrm{Al}_{2} \mathrm{TiO}_{5}$ to its original condition by thermal annealing at $>1400^{\circ} \mathrm{C}$. 


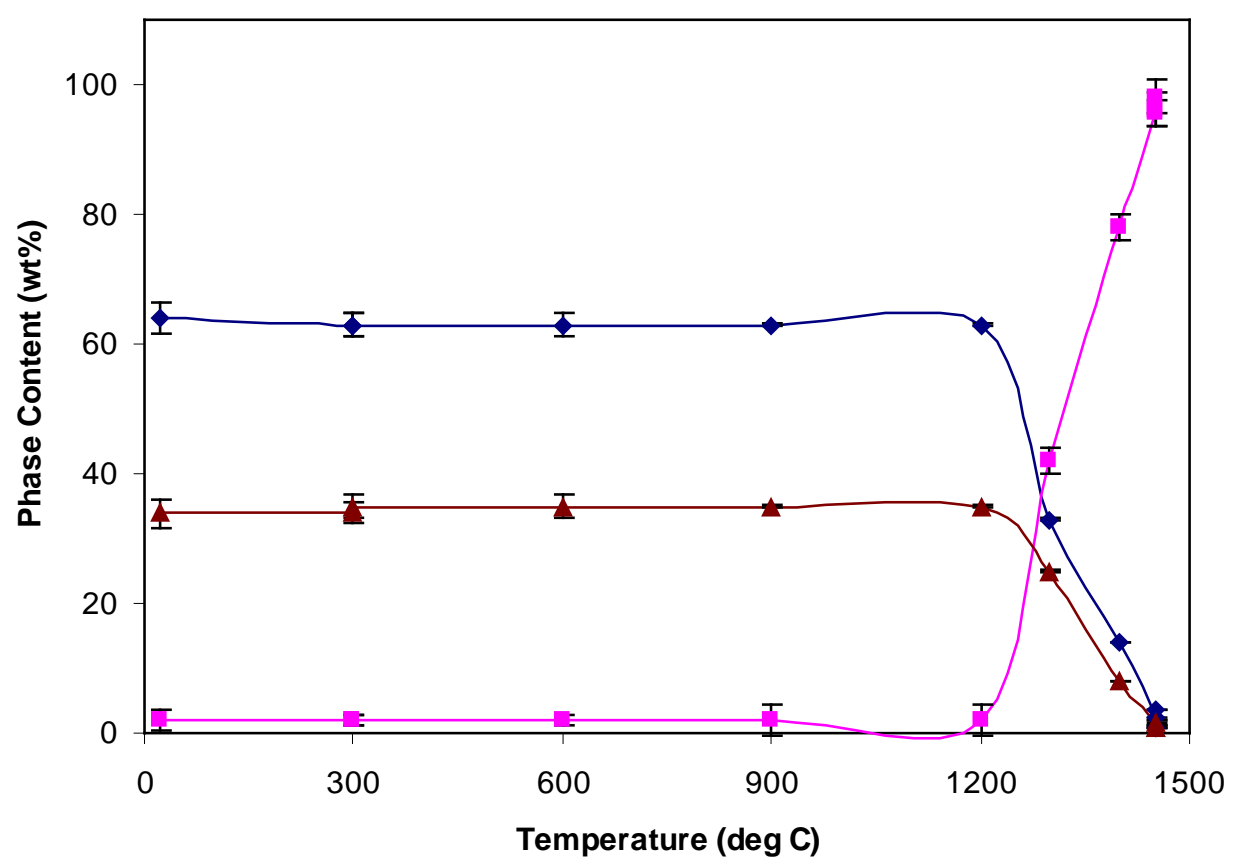

Fig. 8: Reformation of $\mathrm{Al}_{2} \mathrm{TiO}_{5}$ through self-recovery in decomposed $\mathrm{Al}_{2} \mathrm{TiO}_{5}$. [Legend: $\mathbf{\square}=\mathrm{Al}_{2} \mathrm{TiO}_{5}$;

$$
\checkmark \text { corundum; } \boldsymbol{\Delta} \text { = rutile] }
$$

\section{CONCLUSIONS}

The effect of grain size on the thermal stability of $\mathrm{Al}_{2} \mathrm{TiO}_{5}$ at $1100^{\circ} \mathrm{C}$ and the phenomenon of self-recovery in the temperature range $20-1400^{\circ} \mathrm{C}$ have been dynamically examined by neutron diffraction. The thermal stability of $\mathrm{Al}_{2} \mathrm{TiO}_{5}$ increases as the grain size increases probably through the formation of stress-relief microcracks. The process of phase decomposition is reversible and selfrecovery occurs readily when decomposed $\mathrm{Al}_{2} \mathrm{TiO}_{5}$ is re-heated above $1300^{\circ} \mathrm{C}$.

\section{ACKNOWLEDGMENTS}

This work was supported by funding from the Australian Institute of Nuclear Science and Engineering (AINSE Awards 04/207 \& 05/206). We are grateful to our colleague, E/Prof. B. O'Connor, for advice on Rietveld analysis of XRD data. We thank Dr. M. Avdeev of the Bragg Institute of ANSTO for experimental assistance in the collection of MRPD data. We also thank Mr. A. Jones of Alcoa and Ms E. Miller of CMR for assistance with SEM work.

\section{REFERENCES}

${ }^{1}$ A.E. Austin and C.M. Schwartz, The Crystal Structure of Aluminium Titanate, Acta Cryst. 6, 812-13 (1953).

${ }^{2}$ B. Morosin and R.W. Lynch, Structure Studies on $\mathrm{Al}_{2} \mathrm{TiO}_{5}$ at Room Temperature and at $600^{\circ} \mathrm{C}$, Acta Cryst. B. 28, 1040-1046 (1972).

${ }^{3}$ H.A.J. Thomas and R. Stevens, Aluminium Ttitanate - a Literature Review. Part 1: Microcracking Phenomena, Br. Ceram Trans. J. 88, 144-90 (1989). 
${ }^{4}$ H.A.J. Thomas and R. Stevens, Aluminium Titanate - A literature Review. Part 2: Engineering Properties and Thermal Stability, Br. Ceram Trans. J. 88, 184-190 (1989).

${ }^{5}$ V. Buscaglia, P. Nanni, G. Battilana, G. Aliprandi, and C. Carry, Reaction Sintering of Aluminium Titanate: 1 - Effect of MgO Addition, J. Eur. Ceram. Soc. 13, 411-417 (1994)

${ }^{6}$ G. Tilloca, Thermal Stabilization of Aluminium Titanate and Properties of Aluminium Titanate Solid Solutions, J. Mater. Sci. 26, 2809-2814 (1991).

${ }^{7}$ E., Kato, K. Daimon and Y. Kobayashi, Factors Affecting Decomposition Temperature of $\beta-\mathrm{Al}_{2} \mathrm{TiO}_{5}$, J. Am. Ceram. Soc. 63, 355-356 (1980).

${ }^{8}$ R.W. Grimes and J. Pilling, Defect Formation in $\beta-\mathrm{Al}_{2} \mathrm{TiO}_{5}$ and its Influence on Structure Stability, $J$. Mater. Sci. 29, 2245-49 (1994).

${ }^{9}$ M. Ishitsuka, T. Sato, T. Endo and M. Shimada, Synthesis and Thermal Stability of Aluminium Titanate Solid Solutions, J. Am. Ceram. Soc. 70, 69-71 (1987).

${ }^{10} \mathrm{~B}$. Freudenberg and A. Mocellin, Aluminum Titanate Formation by Solid-State Reaction of Coarse $\mathrm{Al}_{2} \mathrm{O}_{3}$ and $\mathrm{TiO}_{2}$ Powders, J. Am. Ceram. Soc. 71, 22-28 (1988).

${ }^{11}$ B. Freudenberg and A. Mocellin, Aluminium Titanate Formation by Solid State Reaction of $\mathrm{Al}_{2} \mathrm{O}_{3}$ and $\mathrm{TiO}_{2}$ Single Crystals, J. Mater. Sci. 25, 3701-3708 (1990).

${ }^{12}$ I.M. Low, D. Lawrence, and R.I. Smith, Factors Controlling the Thermal Stability of Aluminium Titanate in Vacuum, J. Am. Ceram. Soc. 88, 2957-2961 (2005).

${ }^{13}$ I.M. Low, Z. Oo and B. O’Connor, Effect of Atmospheres on the Thermal Stability of Aluminium Titanate, Physica B: Condensed Matter, 385-386, 502-504, (2006).

${ }^{14}$ I.M. Low and Z. Oo, Reformation of Phase Composition in Decomposed Aluminium Titanate, Mater. Chem. \& Phys. 111, 9-12 (2008).

${ }^{15}$ A. Jones and I.M. Low, Microstructural Characteristics of Isothermally-Aged Aluminium Titanate Ceramics, pp.185-186 in Proc. of AUSTCERAM 2002 (Eds. I.M. Low \& D.N. Phillips), 30 Sept - 4 Oct. 2002, Perth, WA.

${ }^{16}$ Y. Ohya, Z. Nakagawa and K. Hamano, Crack Healing and Bending Strength of Aluminium Titanate Ceramics at High Temperature, J. Am. Ceram. Soc. 71, C23-C33 (1988).

${ }^{17}$ Y. Ohya and Z. Nakagawa, Grain Boundary Microcracking Due to Thermal Expansion of $\mathrm{Al}_{2} \mathrm{TiO}_{5}$ Ceramics at High Temperature, J. Am. Ceram. Soc. 70, C184-C186 (1987).

${ }^{18}$ K. Hamano, Y. Ohya and Z. Nakagawa, pp. 129-137 in Int. Journal of High Tech. Ceram. Elsevier Science Publishers Ltd., UK. (1985)

${ }^{19}$ E.N. Maslen, V.A. Streltsov, N.R. Streltsova, N. Ishizawa and Y. Satow, Synchrotron X-Ray Study of the Electron Density in $\alpha-\mathrm{Al}_{2} \mathrm{O}_{3}$, Acta Crystallographica, B49, 937-980 (1993).

${ }^{20}$ T. Epicier, G. Thomas, H. Wohlfromm and J.S. Moya, High Resolution Electron Microscopy Study of the Cationic Disorder in $\mathrm{Al}_{2} \mathrm{TiO}_{5}$, J. Mater. Res. 6, 138-145 (1991).

${ }^{21}$ C.J. Howard, T.M. Sabine and F. Dickson, Structural and Thermal Parameters for Rutile and Anatase, Acta Cryst. B, 47, 462-468 (1991). 